\title{
Image quality and quantification accuracy dependence on patient body mass in ${ }^{89} \mathrm{Zr}$ PET/ CT imaging
}

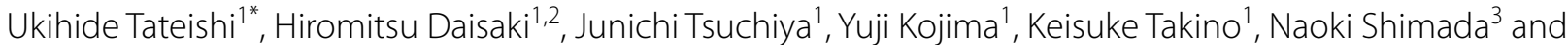 \\ Kota Yokoyama'
}

\begin{abstract}
*Correspondence: ttisdrnm@tmd.ac.jp

${ }^{1}$ Department of Diagnostic Radiology, Graduate School of Medicine, Tokyo Medical and Dental University, Tokyo, Japan

Full list of author information is available at the end of the article
\end{abstract}

\begin{abstract}
Background: This study was conducted to clarify how patient body mass affects the image quality and quantification accuracy of images obtained using ${ }^{89} \mathrm{Zr} \mathrm{PET} / \mathrm{CT}$. ${ }^{89} \mathrm{Zr}$ PET/CT images from time-of-flight (TOF) PET/CT and semiconductor (SC) PET/CT were obtained using three types ( $M, L, L L$; corresponding to increasing patient body weight) of custom-made body phantoms designed similarly to the National Electrical Manufacturers Association (NEMA) IEC body phantom. The phantom data were analyzed visually and quantitatively to derive image quality metrics, namely detectability of the 10-mm-diameter hot sphere, percent contrast for the 10-mm-diameter hot sphere $\left(\mathrm{Q}_{\mathrm{H}, 10 \mathrm{~mm}}\right)$, percent background variability $\left(\mathrm{N}_{10 \mathrm{~mm}}\right)$, contrast-to-noise ratio $\left(\mathrm{Q}_{\mathrm{H}, 10 \mathrm{~mm}} /\right.$ $\left.\mathrm{N}_{10 \mathrm{~mm}}\right)$, and coefficient of variation of the background area $\left(\mathrm{CV}_{\mathrm{BG}}\right)$.
\end{abstract}

Results: Visual assessment revealed that all the 10-mm-diameter hot spheres of the three types of phantoms were identifiable on both SC and TOF PET/CT images. The $\mathrm{N}_{10 \mathrm{~mm}}$ and $C V_{B G}$ values were within the proposed reference levels, and decreased with acquisition duration for both PET/CT types. At 10-min acquisition, the $\mathrm{Q}_{H, 10 \mathrm{~mm}} / \mathrm{N}_{10 \mathrm{~mm}}$ of SC PET/CT was greater than the proposed reference level in all phantoms. However, the $\mathrm{Q}_{\mathrm{H}, 10 \mathrm{~mm}} / \mathrm{N}_{10 \mathrm{~mm}}$ of TOF PET/CT was greater than the proposed reference level in M-type phantom alone. All the SUV $V_{B G}$ values were within $1.00 \pm 0.05$ for both PET/CT types.

Conclusions: This study showed that the image quality and quantification accuracy depend on the patient's body mass, suggesting that acquisition time on ${ }^{89} \mathrm{Zr} \mathrm{PET} / \mathrm{CT}$ should be changed according to the patient's body mass.

Keywords: ${ }^{89} \mathrm{Zr}$, PET/CT, Patient's body mass, Time-of-flight, Semi-conductor

\section{Background}

The positron radionucleotide ${ }^{89} \mathrm{Zr}$ has been utilized for PET imaging labeled monoclonal antibodies to date, because long half-life radioisotope is needed for assessment of the circulating probes. ${ }^{89} \mathrm{Zr}$ facilitates high-resolved PET imaging with a short positron range by emitting low-energy $\beta^{+}$rays. After introduction of desferrioxamine $\mathrm{B}$ (DFO) as specific chelator for ${ }^{89} \mathrm{Zr}$ labeling, the number of antibodies and antibody fragments party material in this article are included in the article's Creative Commons licence, unless indicated otherwise in a credit line to the material. If material is not included in the article's Creative Commons licence and your intended use is not permitted by statutory regulation or exceeds the permitted use, you will need to obtain permission directly from the copyright holder. To view a copy of this licence, visit http:// creativecommons.org/licenses/by/4.0/. 
have been approved by the Food and Drug Administration (FDA) for last decade. Over the 17 antibodies including trastuzumab, bevacizumab, cetuximab, and rituximab were labeled with ${ }^{89} \mathrm{Zr}$ for PET imaging [1-5]. Evaluating the target status of tumors is crucial for clinical decision making for patients planning molecular targeting therapy. A wholebody evaluation of target expression with ${ }^{89} \mathrm{Zr}$-trastuzumab PET changes the treatment plan [6]. Based on the results from recent two publications, the authors demonstrated that $89 \mathrm{Zr}$-trastuzumab reflects tumor heterogeneity and supports clinical decision making when HER2 status could not be determined by standard procedures, which allows the selection of a personalized therapy $[7,8]$. Thus, ${ }^{89} \mathrm{Zr}$-monoclonal antibody PET is promising for evaluating patient selection and therapeutic effect.

${ }^{89} \mathrm{Zr}$-monoclonal antibody PET would be utilized for clinical trials of multicenter in the near future. Thus, standardization and harmonization of ${ }^{89} \mathrm{Zr}$ PET/CT have been investigated to date. According to the EANM procedure guideline for tumor imaging: version 2.0, EARL accreditation enhances the quality standards of PET/CT investigations to minimize the technical factors and ensures performance of PET/CT machines by harmonization [9]. EARL has also ${ }^{89} \mathrm{Zr}$ PET/CT accreditation to ensure quantitative image quality using ${ }^{89} \mathrm{Zr}$ labeled pharmaceuticals. In this context, several investigators have addressed multicenter harmonization of $89 \mathrm{Zr}$ PET/CT to ensure image quality and quantitation accuracy [10-13]. However, the results of the previous studies did not contain the problems affected by the patient's body mass. PET imaging of larger patients is affected by high noise levels, because of the considerable intrinsic attenuation.

The purpose of this study was to clarify how patient body mass affects the image quality and quantification accuracy of images obtained using ${ }^{89} \mathrm{Zr}$ PET/CT.

\section{Methods}

\section{Phantom experiments}

Two PET/CT machines (Celesteion, time-of-flight [TOF] PET/CT and Cartesion Prime, semi-conductor [SC] PET/CT, Canon Medical Systems, Otawara, Tochigi, Japan) were investigated for study. The SC PET/CT is equipped with a silicon photomultiplier (SiPM). Three types of body phantoms including 30 (M type), 33 (L type), and 36 (LL type) $\mathrm{cm}$ in the major axis, corresponding to $60 \mathrm{~kg}$, $80 \mathrm{~kg}$, and $100 \mathrm{~kg}$ body weight, respectively, were designed similarly to National Electrical Manufacturers Association (NEMA) IEC body phantom by custom made (Fig. 1). These phantoms contained six spheres with inner diameters of 10,13,17, 22, 28, and $37 \mathrm{~mm}$. All spheres were filled with ${ }^{89} \mathrm{Zr}$ solutions to achieve 10:1 sphere-to-background activity concentration ratio based on the prior study of international standardization [8]. This study did not include human data and personal information.

\section{Data acquisition}

The phantoms underwent a low-dose $\mathrm{CT}$ acquisition with auto-exposure of an X-ray tube current followed by PET acquisition for each scan. A 20-min-per-bed-position 1-bed-position for list mode acquisition and 5-, 10-, and 15-min-per-bed-position 2-bed-position acquisition were subsequently obtained for three types of phantoms (Fig. 2). PET images of SC PET/CT were reconstructed using parameters featuring ordered subset expectation maximization (OSEM) into a $336 \times 336$ matrix; voxel size 


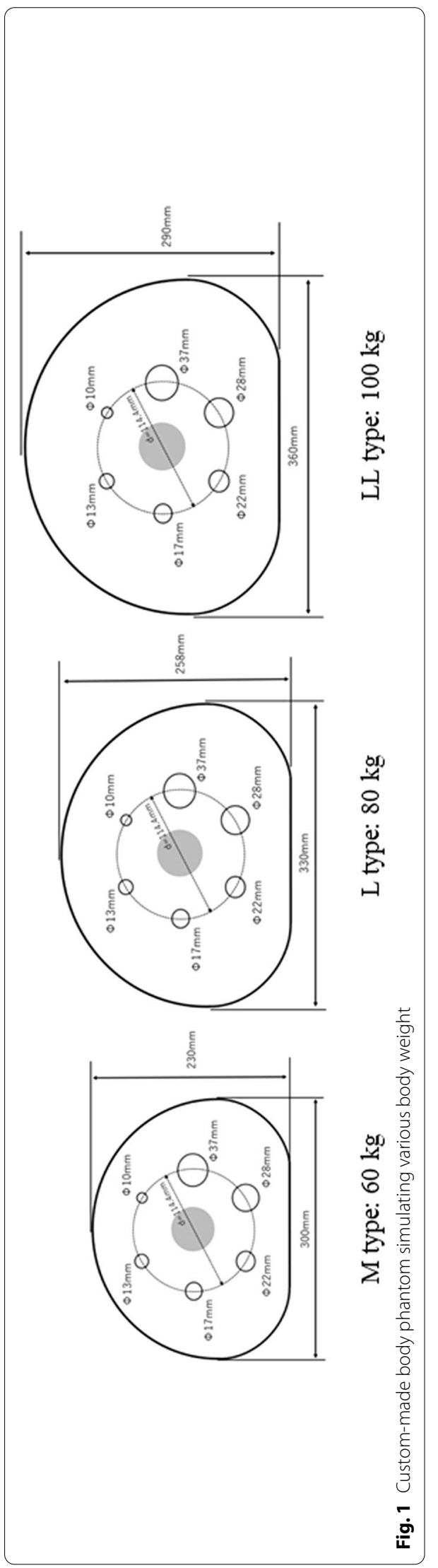




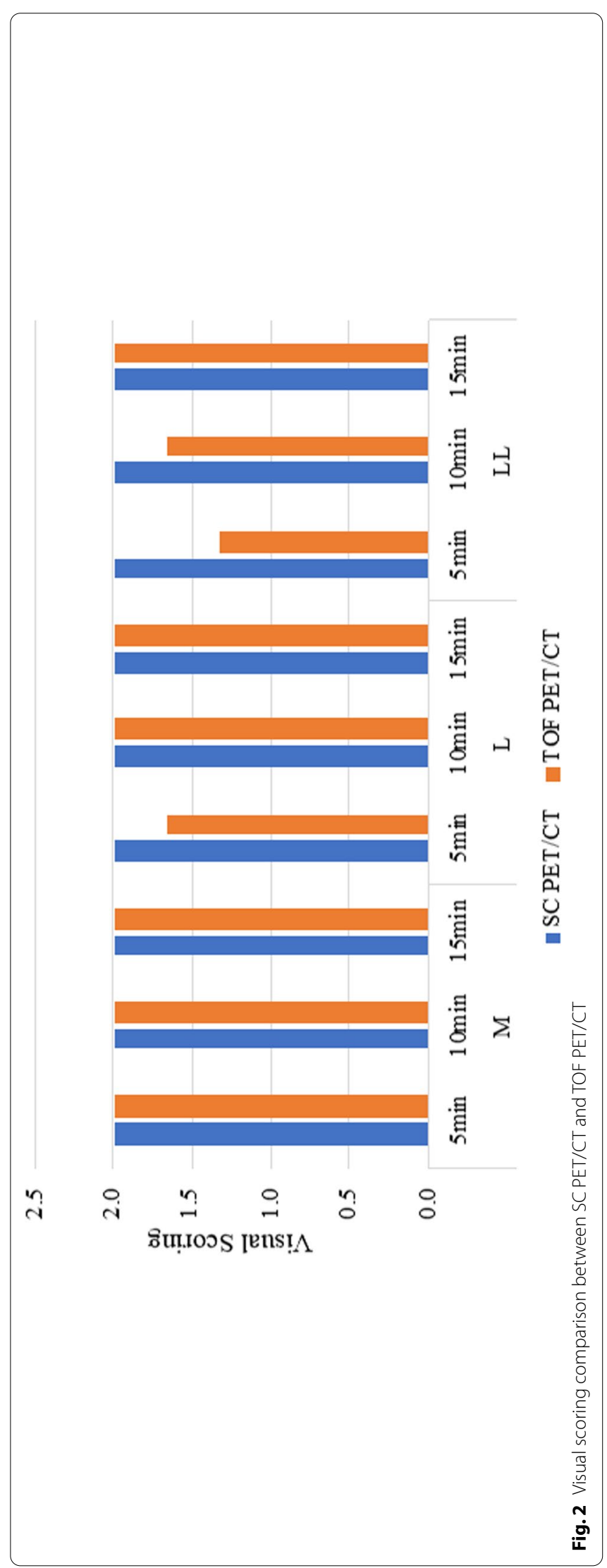


$9.44 \mu \mathrm{l}(2.11 \times 2.11 \times 2.11 \mathrm{~mm})$ with two iterations, 12 subsets, a 3.0-mm 3D Gaussian filter, and active corrections by CT-based attenuation, scatter, TOF, and point-spread function (PSF). PET images of TOF PET/CT were also reconstructed using parameters featuring OSEM into a $336 \times 336$ matrix; voxel size $8.47 \mu \mathrm{l}(2.04 \times 2.04 \times 2.04 \mathrm{~mm})$ with three iterations, 10 subsets, a $6.0-\mathrm{mm}$ 3D Gaussian filter, and corrections by CT-based attenuation, scatter, TOF, and PSF. Reconstructed images were evaluated by quantitative methods. Image analysis was performed using RAVAT (Nihon Medi-Physics Co., Ltd.) [14].

\section{Image analysis}

Detectability of the 10-mm-diameter hot sphere was visually assessed by three nuclear medicine technologists in a three-step scale ( 0 , not visualized; 1 , visualized, but similar hot spots are observed; and 2, identifiable). The VOX-BASE/MANAGER (J-MAC SYSTEM, INC., Japan) was used to display PET images using an invert gray scale with an upper level of 10 and a lower level of 0 (SUV-scaled).

Quantitative analysis of image quality was performed for each image in accordance with the guidelines of the Japanese Society of Nuclear Medicine (JSNM) [15]. The percent contrast for the $10-\mathrm{mm}$ hot sphere $\left(\mathrm{Q}_{\mathrm{H}, 10 \mathrm{~mm}}\right)$, the percent background variability $\left(\mathrm{N}_{10 \mathrm{~mm}}\right)$ for the 10-mm circular region-of-interest (ROI), $\mathrm{Q}_{\mathrm{H}, 10 \mathrm{~mm}} / \mathrm{N}_{10 \mathrm{~mm}}$ ratio, and the coefficient of variation on the background area $\left(\mathrm{CV}_{\mathrm{BG}}\right)$ (image noise level) were calculated. The background standardized uptake value $\left(\mathrm{SUV}_{\mathrm{BG}}\right)$, which reflects the accuracy of the calibration, was evaluated by the average value of SUV calculated by 12 ROIs with a diameter of $37 \mathrm{~mm}$ placed in the $\mathrm{BG}$ region, also in accordance with the guidelines of the JSNM [15]. The recovery coefficient (RC) of all hot spheres was quantified using $\mathrm{RC}_{\text {max }}$ and $\mathrm{RC}_{\text {peak }}$ (according to the QIBA calculation algorithm) as indicators as shown in Eq. 1 and Eq. $2[14,15]$. Based on EARL accreditation manual Ver 2.0, the calibration quality control for ${ }^{89} \mathrm{Zr}$ is similar to the ${ }^{18} \mathrm{~F}$ calibration phantom procedure, because ${ }^{89} \mathrm{Zr}$ RCs are directly related to the RCs obtained with ${ }^{18} \mathrm{~F}[10,12]$.

$$
\begin{aligned}
R C_{\text {max }, i} & =\frac{S U V_{\max , i}}{10} \\
R C_{\text {peak }, i} & =\frac{S U V_{\text {peak }, i}}{10}
\end{aligned}
$$

\section{Statistical analysis}

Differences between groups for quantification data were analyzed using the parametric Student $\mathrm{t}$ test. A $\mathrm{P}$ value $<0.05$ was considered significant. Statistical analysis was performed using SPSS version 28.0 (IBM-SPSS Japan Inc, Tokyo, Japan).

\section{Results}

\section{Detectability}

Visual assessment by SC PET/CT showed that all the 10-mm-diameter hot sphere were identifiable (Fig. 2). In contrast, detectability of the 10-mm-diameter hot sphere depended on scan duration in L type and LL type phantoms on TOF PET/CT. All the 
10-mm-diameter hot sphere of three types of phantoms were visually identifiable on both PET/CT. The $\mathrm{Q}_{\mathrm{H}, 10 \mathrm{~mm}}, \mathrm{~N}_{10 \mathrm{~mm}}, \mathrm{Q}_{\mathrm{H}, 10 \mathrm{~mm}} / \mathrm{N}_{10 \mathrm{~mm}}$, and $\mathrm{CV}_{\mathrm{BG}}$ as a function of scan duration in all phantoms are shown in Fig. 3. The $\mathrm{Q}_{\mathrm{H}, 10 \mathrm{~mm}}$ did not correlate with acquisition duration. For $\mathrm{N}_{10 \mathrm{~mm}}$, significant differences were observed in the 10 -mm-spheredetectable values among the three types of phantoms. The $\mathrm{N}_{10 \mathrm{~mm}}$ and $\mathrm{CV}_{\mathrm{BG}}$ decreased with acquisition duration for both PET/CT. The $\mathrm{Q}_{\mathrm{H}, 10 \mathrm{~mm}} / \mathrm{N}_{10 \mathrm{~mm}}$ increased mostly with acquisition duration. SC PET/CT was capable of showing enough $\mathrm{Q}_{\mathrm{H}, 10 \mathrm{~mm}} / \mathrm{N}_{10 \mathrm{~mm}}$ greater than 2.8 except for LL type phantom with 5-min acquisition. However, the $\mathrm{Q}_{\mathrm{H}, 10 \mathrm{~mm}} / \mathrm{N}_{10 \mathrm{~mm}}$ of TOF PET/CT at 5-min acquisition was less than 2.8 in all phantoms. At 10-min acquisition, the $\mathrm{Q}_{\mathrm{H}, 10 \mathrm{~mm}} / \mathrm{N}_{10 \mathrm{~mm}}$ of SC PET/CT was greater than 2.8 in all phantoms, whereas the $\mathrm{Q}_{\mathrm{H}, 10 \mathrm{~mm}} / \mathrm{N}_{10 \mathrm{~mm}}$ of TOF PET/CT was greater than 2.8 in M type phantom alone. All $\mathrm{Q}_{\mathrm{H}, 10 \mathrm{~mm}} / \mathrm{N}_{10 \mathrm{~mm}}$ at 15 -min acquisition were greater than 2.8 in all phantoms for both of SC PET/CT and TOF-PET/CT.

\section{Accuracy}

The $\mathrm{SUV}_{\mathrm{BG}}$ of both scanners in three types of phantoms is shown in Fig. 4. The $\mathrm{SUV}_{\mathrm{BG}}$ tended to be greater depending on phantom size. All the $\mathrm{SUV}_{\mathrm{BG}}$ were within $1.00 \pm 0.05$ for both PET/CT. For TOF PET/CT, mean SUV of LL type was significantly greater than those of $M$ type $(p=0.0085)$ or L type $(p=0.0092)$. Meanwhile, for SC PET/CT, mean SUV of LL type was significantly greater than those of M type $(\mathrm{p}=0.0038)$. However, no significant difference was found in mean SUV obtained by SC PET/CT between L type and $\mathrm{M}$ type, or LL type and $\mathrm{L}$ type. The relationship between $\mathrm{RC}_{\max }$ or $\mathrm{RC}_{\text {peak }}$ and sphere diameter is shown in Fig. 5. Both of the $\mathrm{RC}_{\max }$ and $R C_{\text {peak }}$ of $\mathrm{L}$ type were the highest, but the differences were not statistically significant. The $\mathrm{RC}_{\max }$ was affected by statistical noise for both $\mathrm{PET} / \mathrm{CT}$, while the $\mathrm{RC}_{\text {peak }}$ was stable and robust for statistical noise. However, RC peak is susceptible to underestimation of quantitative value due to partial volume effect.

\section{Discussion}

The purpose of this study was to investigate whether the image quality and quantification accuracy were affected by the patient's body mass on ${ }^{89} \mathrm{Zr}$ PET/CT. Expectedly, we found that 10-mm-diameter hot sphere could be detected for 5-min acquisition by both SC PET/CT and TOF-PET/CT. However, the detectability depended on PET/CT machines to a similar degree in all types of phantoms.

The $\mathrm{N}_{10 \mathrm{~mm}}$ reflects background variability, and all the $\mathrm{N}_{10 \mathrm{~mm}}$ examined in our study is greater than the proposed reference level. The technique of PSF and TOF contribute to improving contrast in the 10-mm-diameter hot sphere and resulted in increased background variability. The $\mathrm{Q}_{\mathrm{H}, 10 \mathrm{~mm}} / \mathrm{N}_{10 \mathrm{~mm}}$ assures 10 -mm-diameter hot sphere visibility, but this metric depends on type of PET/CT scanner models and acquisition duration. In our study, the SC PET/CT showed enough $\mathrm{Q}_{\mathrm{H}, 10 \mathrm{~mm}} / \mathrm{N}_{10 \mathrm{~mm}}$ greater than the proposed reference level except for LL phantom with 5-min acquisition. However, the $\mathrm{Q}_{\mathrm{H}, 10 \mathrm{~mm}}$ / $\mathrm{N}_{10 \mathrm{~mm}}$ of TOF PET/CT was mostly less than the proposed reference level at 5- or 10-min acquisition in all phantoms. The $\mathrm{Q}_{\mathrm{H}, 10 \mathrm{~mm}} / \mathrm{N}_{10 \mathrm{~mm}}$ implies information of the $10-\mathrm{mm}$ diameter hot sphere contrast and the background variability, and the balance of contrast and noise is valuable for visual detectability of small hot lesion. In this context, long scan 


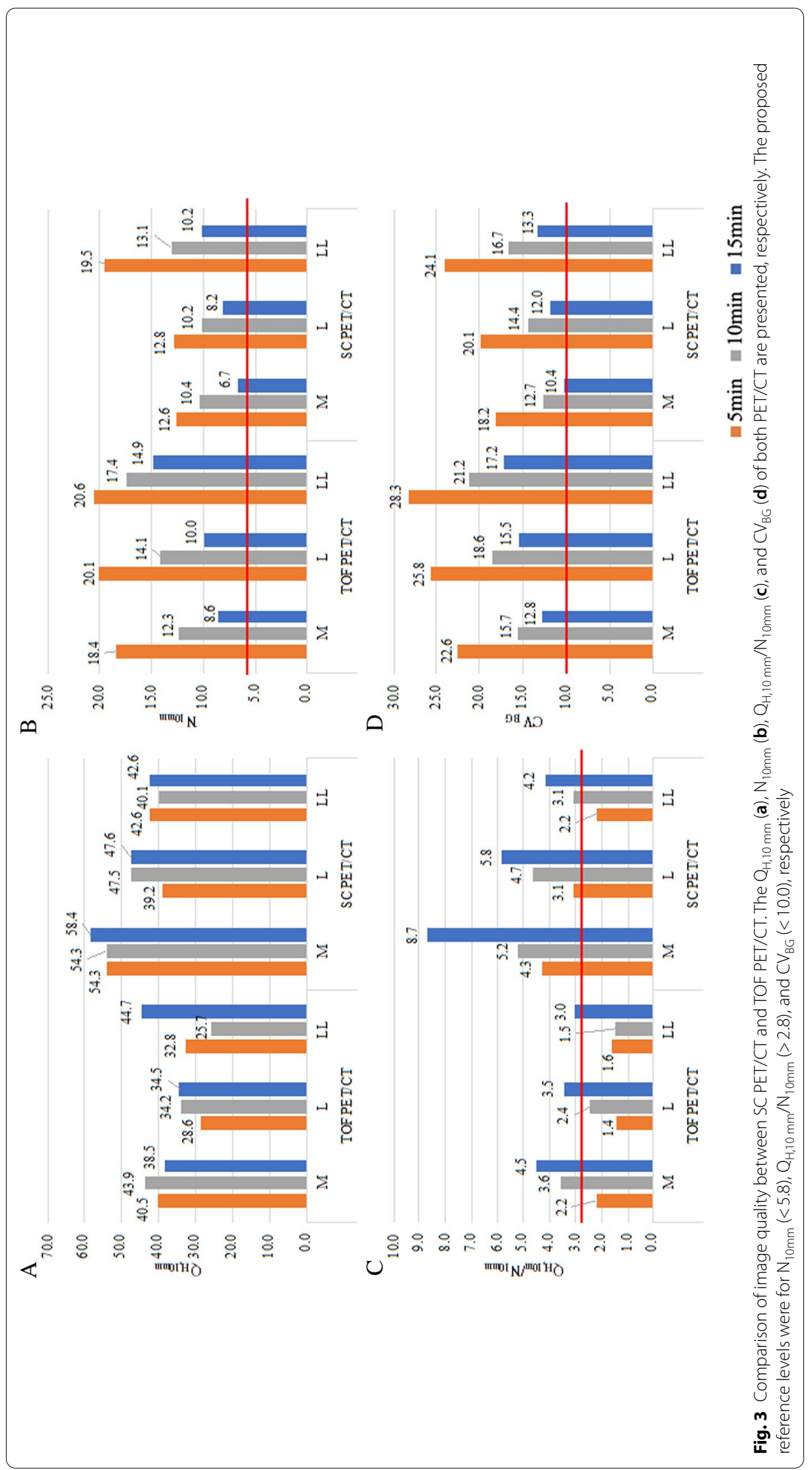




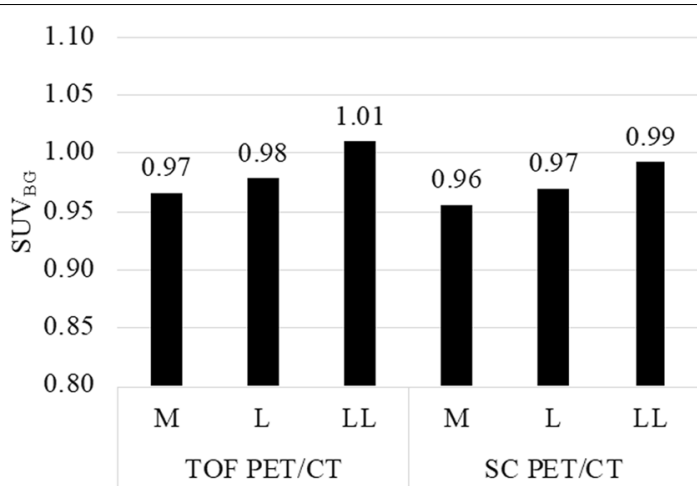

Fig. $4 S_{S U V}$ of both PET/CT scanners in three types of phantoms. The $S U V_{B G}$ increases according to

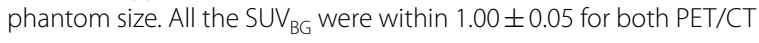

duration would be required for TOF PET/CT. All the $\mathrm{CV}_{\mathrm{BG}}$ calculated in our study were greater than the proposed reference level and decreased with acquisition duration for both PET/CT. The $\mathrm{CV}_{\mathrm{BG}}$ is reproducible metric and has been used for standardization of ${ }^{18} \mathrm{FDG}$ PET/CT in oncology [16-20]. The use of $\mathrm{CV}_{\mathrm{BG}}$ might facilitate international standardization to reduce variability and global ${ }^{89} \mathrm{Zr}$ PET/CT studies [21]. However, the $\mathrm{CV}_{\mathrm{BG}}$ cannot reflect the effective spatial resolution of the scanner as directly as the $\mathrm{RC}_{\max }$ or $\mathrm{RC}_{\text {peak }}$. Both metrics are recommended to standardization on ${ }^{89} \mathrm{Zr}$ PET/CT.

In our study, we found that TOF PET/CT was capable of enough detectability by 10-min acquisition per bed position when scanning patient of middle-sized body mass. However, when we scan patient of large-sized body mass, at least 15-min acquisition per bed position would be preferable. In contrast, our findings that 5-min acquisition per bed position by SC PET/CT represented enough detectability when scanning patient of middle-sized body mass. It should be highlighted that SC PET/CT machine is adequate for whole-body scan of ${ }^{89} \mathrm{Zr}$ PET/CT. Nevertheless, when we scan patient of large-sized body mass, at least 10-min acquisition per bed position is required.

Our study showed that the image quality and quantification accuracy was affected by the patient's body mass on ${ }^{89} \mathrm{Zr}$ PET/CT. These results were mirrored to the previous results of ${ }^{18} \mathrm{~F}$-FDG PET/CT. The main differences between ${ }^{18} \mathrm{~F}$ and ${ }^{89} \mathrm{Zr}$ are the practical range of positron provided by ${ }^{18} \mathrm{~F}$ and ${ }^{89} \mathrm{Zr}$ and cascade $\gamma$-ray $(909 \mathrm{keV})$ from each isotope. How these two issue affect image quality was not fully elucidated, but our results revealed that affection to detectability and accuracy were clinically limited.

Both of the $\mathrm{RC}_{\max }$ and $\mathrm{RC}_{\text {peak }}$ of L type were the highest among all phantoms, but the differences were not statistically significant. The precise reason why the $L$ type showed the highest values was unclear, but it may be due to large contribution of noise specific to the L type, or inaccurate alignment of the $10-\mathrm{mm}$ hot sphere to the slice center. These can be verified by further multiple re-examinations.

Kaalep and the colleagues suggested that RC curves derived from ${ }^{89} \mathrm{Zr}$ phantom using quantitative metrics of $\mathrm{RC}_{\max }$ and $\mathrm{RC}_{\text {peak }}$ resulted in increased variability possibly due to activity measurement and phantom filling procedures [12]. This observation is in agreement with our results, because when we investigated both of SC PET/CT and TOF PET/ $\mathrm{CT}$, we observed that there was variable bias in the relationship between $\mathrm{RC}_{\max }$ or $\mathrm{RC}_{\text {peak }}$ and sphere diameter. Moreover, we observed that $\mathrm{RC}_{\text {peak }}$ showed variable bias minimally 


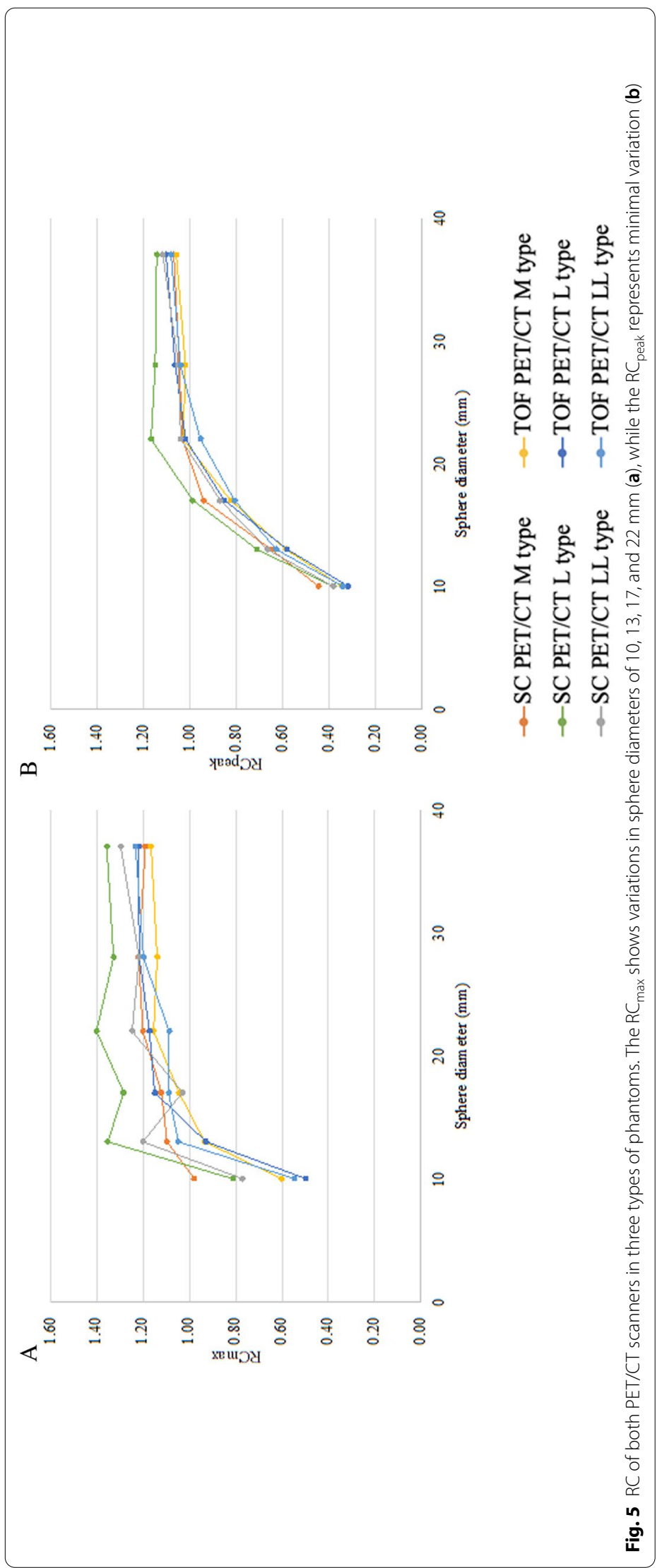


was similar to the results of the previous study using calibration QC and NEMA phantom $\mathrm{QC}$ (12). Altogether, the observation discussed above indicate that $\mathrm{RC}_{\text {peak }}$ is suggestive metric for data comparison among PET/CT systems.

\section{Conclusions}

We demonstrated effects of patient body mass on image quality and quantification accuracy of images obtained using ${ }^{89} \mathrm{Zr}$ PET/CT, indicating that acquisition time should be changed according to the patient's body mass. The $\mathrm{RC}_{\text {peak }}$ shows minimal variability compared to $\mathrm{RC}_{\max }$ on ${ }^{89} \mathrm{Zr}$ PET/CT, but the underlying precise mechanism of this evidence is unknown. Further investigation is required to clarify optimal metrics for comparison among PET/CT systems.

\section{Acknowledgements}

The authors thank the staff of Telix Pharmaceuticals Japan for technical support. The authors also thank Guideline Committee of Japan Radiological Society (JRS) for their vulnerable assistance in edit of manuscript and for their helpful suggestions. We have also been given helpful suggestions by Daniel C Sullivan, MD and Alexander Guimaraes, MD, Steering Committee, Quantitative Imaging Biomarkers Alliance (QIBA), Radiological Society of North America (RSNA) and Shigeki Aoki, MD, Chair of Steering Committee, J-QIBA, JRS.

\section{Authors' contributions}

UT conceived of the study, participated in data collection, study design and coordination, and draft the manuscript. HD, $J T$, and KY helped to draft the manuscript, analyzed the acquired data, and participated in data collection. YK and KT helped to collect data and analysis. All authors read and approved the final manuscript.

Funding

None of the authors has a financial relationship with a commercial entity that has an interest in the subject of this article.

Availability of data and materials

Not applicable.

\section{Declarations}

Ethics approval and consent to participate

This study does not contain any studies with human participants or animals performed by any of the authors.

\section{Consent for publication}

Not applicable.

\section{Competing interests}

The authors declare that they have no competing interests.

\section{Author details}

${ }^{1}$ Department of Diagnostic Radiology, Graduate School of Medicine, Tokyo Medical and Dental University, Tokyo, Japan. ${ }^{2}$ Department of Radiological Technology, Gunma Prefectural College of Health Sciences, Gunma, Japan. ${ }^{3}$ Department of Diagnostic Radiology, Cancer Institute Hospital, Tokyo, Japan.

Received: 13 August 2021 Accepted: 14 October 2021

Published online: 30 October 2021

\section{References}

1. Verel I, Visser GW, van Dongen GA. The promise of immuno-PET in radioimmunotherapy. J Nucl Med. 2005:46(suppl):164S-171S.

2. Zalutsky MR. Potential of immuno-positron emission tomography for tumor imaging and immunotherapy planning. Clin Cancer Res. 2006;12:1958-60.

3. Reichert JM. Monoclonal antibodies as innovative therapeutics. Curr Pharm Biotechnol. 2008;9:423-30.

4. Zhang Y, Hong H, Cai W. PET tracers based on zirconium-89. Curr Radiopharm. 2011;4:131-9.

5. Verhoeff SR, van Es SC, Boon E, van Helden E, et al. Lesion detection by [89Zr]Zr-DFO-girentuximab and [18F] FDG-PET/CT in patients with newly diagnosed metastatic renal cell carcinoma. Eur J Nucl Med Mol Imaging. 2019;46:1931-9.

6. Dijkers EC, Kosterink JG, Rademaker AP, et al. Development and characterization of clinical-grade 89Zr-trastuzumab for HER2/neu immunoPET imaging. J Nucl Med. 2009;50:974-81. 
7. Bensch F, Brouwers AH, Lub-de Hooge MN, de Jong JR, van der Vegt B, Sleijfer S, et al. (89)Zr-trastuzumab PET supports clinical decision making in breast cancer patients, when HER2 status cannot be determined by standard work up. Eur J Nucl Med Mol Imaging. 2018;45(13):2300-6.

8. Gebhart G, Lamberts LE, Wimana Z, Garcia C, Emonts P, Ameye L, et al. Molecular imaging as a tool to investigate heterogeneity of advanced HER2-positive breast cancer and to predict patient outcome under trastuzumab emtansine (T-DM1): the ZEPHIR trial. Ann Oncol. 2016;27(4):619-24.

9. Boellaard R, Delgado-Bolton R, Oyen WJG, Giammarile F, Tatsch K, Eschner W, et al. FDG PET/CT: EANM procedure guidelines for tumour imaging: version 2.0. Eur J Nucl Med Mol Imaging. 2014;42:328-54.

10. Makris NE, Boellaard R, Visser EP, et al. Multicenter harmonization of 89Zr PET/CT performance. J Nucl Med. 2014;55:264-7.

11. Soderlund AT, Chaal J, Tjio G, et al. Beyond 18F-FDG: characterization of PET/CT and PET/MR scanners for a comprehensive set of positron emitters of growing application-18F, 11C, 89Zr, 124l, 68Ga and 90Y. J Nucl Med. 2015;56:1285-91.

12. Kaalep A, Huisman M, Sera T, et al. Feasibility of PET/CT system performance harmonisation for quantitative multicentre 89Zr studies. EJNMMI Phys. 2018;5:26.

13. Christian PE, Williams SP, Burrell L, et al. Optimization of 89Zr PET imaging for improved multisite quantification and lesion detection using an anthropomorphic phantom. J Nucl Med Technol. 2020;48:54-7.

14. Daisaki H, Kitajima K, Nakajo M, et al. Usefulness of semi-automatic harmonization strategy of standardized uptake values for multicenter PET studies. Sci Rep. 2021;11:8517.

15. Fukukita H, Suzuki K, Matsumoto K, et al. Japanese guideline for the oncology FDG-PET/CT data acquisition protocol: synopsis of Version 20. Ann Nucl Med. 2014;28(7):693-705.

16. Kinahan P, Wahl R, Shao L, Frank R, Perlman E. The QIBA profile for quantitative FDG-PET/CT oncology imaging. J Nucl Med. 2014;55:1520.

17. QIBA-PET/CT. QIBA Profile FDG-PET/CT as an Imaging Biomarker Measuring Response to Cancer Therapy. Radiol Soc North Am. 2016:75.

18. Westerterp M, Pruim J, Oyen W, et al. Quantification of FDG PET studies using standardised uptake values in multicentre trials: effects of image reconstruction, resolution and ROI definition parameters. Eur J Nucl Med Mol Imaging 2007;34:392-404.

19. Sunderland JJ, Christian PE. Quantitative PET/CT scanner performance characterization based upon the Society of nuclear medicine and molecular imaging clinical trials network oncology clinical simulator phantom. J Nucl Med. 2015;56:145-52.

20. Kaalep A, Sera T, Rijnsdorp S, et al. Feasibility of state of the art PET/CT systems performance harmonisation. Eur J Nucl Med Mol Imaging. 2018;45(8):1344-61.

21. Jauw YWS, Heijtel DF, Zijlstra JM, et al. Noise-induced variability of immuno-PET with zirconium-89-labeled antibodies: an analysis based on count-reduced clinical images. Mol Imaging Biol. 2018;20:1025-34.

\section{Publisher's Note}

Springer Nature remains neutral with regard to jurisdictional claims in published maps and institutional affiliations.

\section{Submit your manuscript to a SpringerOpen ${ }^{\circ}$ journal and benefit from:}

Convenient online submission

Rigorous peer review

- Open access: articles freely available online

- High visibility within the field

- Retaining the copyright to your article

Submit your next manuscript at $\gg$ springeropen.com 